\title{
ACCESSORY PERONEUS BREVIS TENDON - A CASE REPORT
}

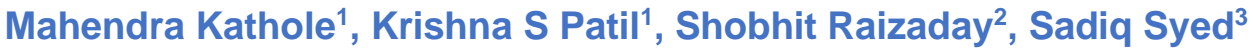 \\ 1. Department of Anatomy, VMMC \& Safdarjung Hospital, New Delhi, India \\ 2. Department of Anatomy, Subharti Medical College, Meerut, India \\ 3. Department of Anatomy, Government Medical College, Miraj, India
}

\begin{abstract}
Introduction: The development of limb musculature takes place between the fifth and seventh weeks of intrauterine life. The genes MYO-D and MYF5 regulate the limb musculature development and any defect in these may lead to either a partial or complete loss or an addition to the normal muscle morphology. This case report presents the observation of an accessory tendon of the Peroneus brevis muscle in the left lower limb of a 70 year old male cadaver during the routine dissection for undergraduate students at Government Medical College, Miraj. The variant insertion of the Peroneus brevis tendon on the calcaneal tubercle is clinically important to note in cases of lateral ankle pain and instability. The presence of an accessory tendon of the peroneus brevis muscle may also be a cause of the longitudinal splitting of the muscle which should be taken into consideration while making a diagnosis and planning surgeries around the lateral aspect of the ankle.
\end{abstract}

Keywords: Peroneus brevis, Accessory tendon, Ankle pain

\section{INTRODUCTION}

The peroneus brevis muscle is a small and short muscle which lies under cover of peroneus longus muscle. It takes origin from the lateral surface of the body of the fibula in the lower two-thirds and the peroneus longus muscle lies medial to it in the peroneal compartment of the leg. The tendon of peroneus brevis runs behind the lateral malleolus along with the peroneus longus tendon and lies in front of the peroneus longus tendons. Peroneus brevis tendon runs downward, forward and on lateral side of the calcaneus bone, in close relation to the calcaneal tubercle and terminates by inserting on the lateral side of the base of the fifth metatarsal tuberosity. The peroneus brevis muscle is a weak plantar flexor and also helps in eversion of the foot and is supplied by the superficial peroneal nerve [1].

Address for Correspondence:

Dr Krishna S. Patil, Post Graduate Student, Department of Anatomy, , VMMC \& Safdarjung Hospital, New Delhi Mob: 9738679296 Email - drkrishnaspatil@gmail.com 
Embryology: Limb development begins between the 5th and 7th weeks of intrauterine life where in most of the limb muscles develop from the paraxial mesoderm under the influence of specific genes MYO-D and MYF5. Any factors affecting them may lead to various anomalies. For example, the partial or complete absence of muscles [2].

\section{OBSERVATIONS}

During the routine academic cadaveric dissection for undergraduate students at Government Medical College, Miraj, we found an accessory tendon of Peroneus Brevis muscle in the left lower limb of a 70 years old male cadaver (Fig. 1). This accessory tendon originated $2 \mathrm{~cm}$ proximal to the tip of the lateral malleolus. It was lying between the main tendon of peroneus brevis anteriorly and peroneus longus tendon posteriorly. It descended on the lateral surface of calcaneal bone and inserted on the peroneal tubercle measuring $3.5 \mathrm{~cm}$ in length and $0.4 \mathrm{~cm}$ in thickness. There was no additional slip to any other tendons or bone. Peroneus brevis in the right leg was normal.

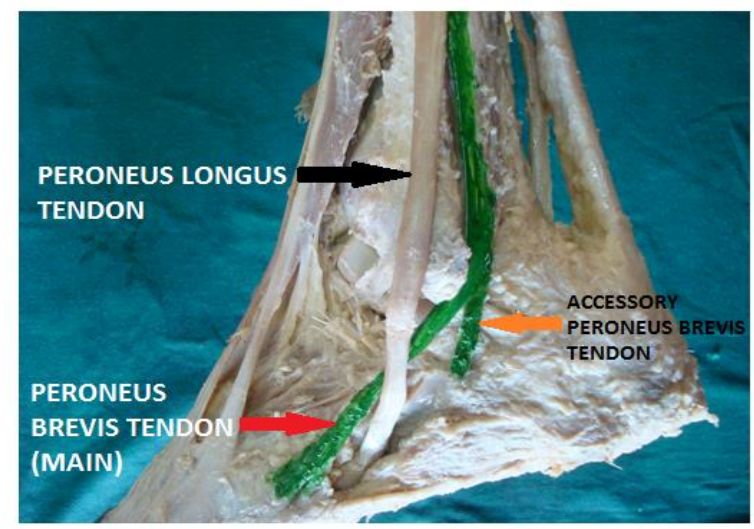

Fig. 1. Dissected left ankle showing accessory Peronius brevis muscle coloured green

\section{DISCUSSION}

The variations in insertion and multiple split tendons are due to a developmental anomaly. Many authors have reported their finding based on how many tendons does the peroneus brevis muscle has. It may be a single tendon with abnormal insertion or may have multiple tendons, inserting at different aspects of the foot bones.

Similar to our case report many authors reported the accessory and other variants of peroneus brevis muscle. Cecava et al, reported a congenital variant insertion of the peroneus brevis tendon on the calcaneal peroneal tubercle with the absence of the tendon distal to the calcaneus. It was observed incidentally in a 24-year old male in magnetic resonance imaging for the evaluation of pain for a suspected ligament injury [3].

Clarkson et al, reported two variants of the peroneus muscle in a 70-year-old white male cadaver and termed them peroneocuboideus muscle and peroneocalcaneocuboideus muscle which were found in the right and left leg respectively and both muscles inserted

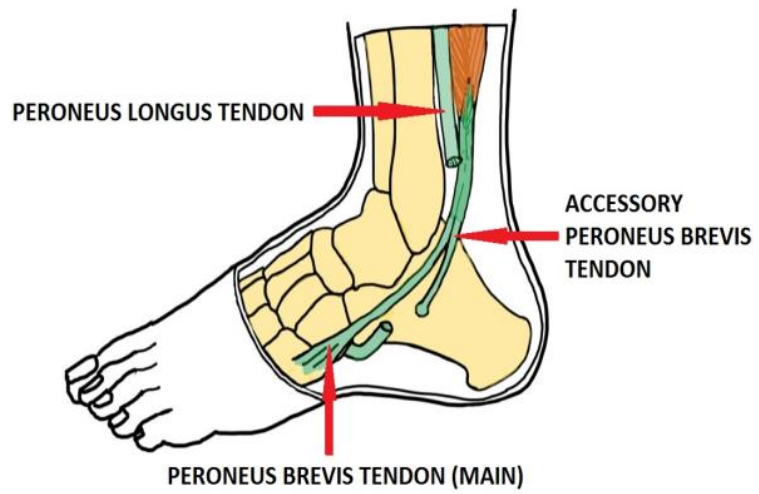

Fig. 2. Schematic representation of Accessory Peroneus brevis Tendon Inserting on peroneal tubercle 
onto the distal lip of the peroneal sulcus of the cuboid bone [4].

Taser et al observed a longitudinal tear in the peroneus brevis tendon and commented that one of the possible causes of the longitudinal tear in the peroneus brevis tendon can be due to an anomalous peroneus tertius muscle with its different origin and insertion points, causing a change in the ankle motion mechanism [5]. It is important to recognise the normal variants of the peroneal tendons, peroneus brevis tendon pseudosubluxation, a bifurcated peroneus brevis tendon, the presence of os perineum and insertion of other accessory muscle-tendon into the peroneus brevis tendon [6].

Prevalence of an accessory muscle (peroneus quartus) was studied by Cheung et al using 136 consecutive ankle magnetic resonance images. They found 14 cases (10\%) having an accessory muscle and the tendon was lying medial and posterior to the other peroneal tendons. The muscle had the variable site of insertion on the peroneus longus tendon, peroneus brevis tendon, calcaneus, and cuboid bone [7].

Accessory tendon inserted on the peroneal tubercle can be used for reconstructive procedures about the lateral aspect of the ankle, especially in anterior dislocation of the peroneal tendons and reconstruction of lateral ligaments [8].

Saupe et al, studied the prevalence of accessory peroneus quartus muscles in 65 volunteers consisting 30 males and 35 females whose age range was between 23-70 years using MR images. 11 (17\%) cases had the peroneus quartus muscle, $19 \%$ of the cases had the musculotendinous junctions of the peroneus brevis muscle. They concluded that anatomic variants may predispose for the peroneal tendon disorders [9].

\section{CONCLUSION}

The Variant congenital insertion of the peroneus brevis tendon on the calcaneal tubercle should be acknowledged. The lateral ankle pain, stenosis, ankle instability, fibular tenosynovitis, subluxation of the peroneal tendons, and longitudinal splitting of the fibularis brevis tendon in radiologic and case studies may be due to presence of a variant peroneus muscles. Therefore, radiologists, clinicians, and surgeons should take into consideration these variations of peroneus brevis muscle while interpreting radiographs, considering various diagnoses, and planning a surgical intervention in and around the lateral ankle.

\section{REFERENCES}

1. Standring S. Gray's Anatomy: The Anatomical basis of Clinical practice. $41 \mathrm{st}$ ed., London: Churchill Livingstone 2016;40:1408.

2. Sadler TW. Langman's medical embryology. 12th ed., Philadelphia : Wolters Kluwer Health/Lippincott Williams \& Wilkins 2012:199-207.

3. Cecava ND, Campbell SE. Peroneus Brevis Tendon Variant Insertion on the Calcaneus. J Radiol Case Rep. 2015;9(5):22-29.

4. Clarkson MJ, Fox JN, Atsas S, Daney BT, Dodson SC, Lambert HW. Clinical implications of novel variants of the fibularis 
(peroneus) quartus muscle inserting onto the cuboid bone: peroneocuboideus and peroneocalcaneocuboideus. J Foot Ankle Surg. 2013;52(1):118-121.

5. Taşer $F$, Shafiq $Q$, Toker S. Coexistence of anomalous $\mathrm{m}$. peroneus tertius and longitudinal tear in the $\mathrm{m}$. peroneus brevis tendon. Eklem Hastalik Cerrahisi. 2009;20(3):165-168.

6. Wang $\mathrm{XT}$, Rosenberg $\mathrm{ZS}$, Mechlin MB, Schweitzer ME. Normal variants and diseases of the peroneal tendons and superior peroneal retinaculum: MR imaging features [published correction appears in Radiographics. 2005 Sep-Oct;25(5):1436.

7. Cheung YY, Rosenberg ZS, Ramsinghani $\mathrm{R}$, Beltran J, Jahss MH. Peroneus quartus muscle: MR imaging features. Radiology. 1997;202(3):745-750.

8. Sobel M, Levy ME, Bohne WH. Congenital variations of the peroneus quartus muscle: an anatomic study [published correction appears in Foot Ankle 1991 Apr;11(5):342]. Foot Ankle. 1990;11(2):81-89.

9. Saupe N, Mengiardi B, Pfirrmann CW, Vienne P, Seifert B, Zanetti M. Anatomic variants associated with peroneal tendon disorders: MR imaging findings in volunteers with asymptomatic ankles. Radiology. 2007;242(2):509-517. 